\title{
EL PADRÓN FISCAL DE 1480 DE LLAMAS DE LA RIBERA (LEÓN). UNA NUEVA FUENTE PARA LA DIPLOMÁTICA SEÑORIAL
}

\author{
THE 1480 TAX CENSUS OF \\ LLAMAS DE LA RIBERA (LEÓN). \\ A NEW SOURCE FOR SEIGNEURIAL DIPLOMATICS
}

\author{
FRANCISCO JAVIER ÁLVAREZ CARBAJAL \\ Universidad de Oviedo
}

Resumen: El padrón fiscal de 1480 de Llamas de la Ribera (León) constituye el único ejemplar de esta tipología hallado en el archivo del linaje de los Quiñones-condes de Luna. A pesar de la utilidad que este tipo de padrones poseen para el desarrollo de estudios históricos, es relativamente poco lo que sabemos de ellos, especialmente desde el punto de vista de la ciencia diplomática. Por ello nos propusimos la realización del estudio y edición de este manuscrito, cuya caracterización puede contribuir a conocer mejor el sistema contributivo y su plasmación documental en el mundo rural leonés de fines de la Edad Media. Partiendo siempre desde el punto de vista del diplomatista y paleógrafo, procedimos a la edición del tenor documental para acometer posteriormente el estudio de sus caracteres internos y externos, intentando comprender el papel jugado por este ejemplar en el contexto de la administración de los concejos pertenecientes al señorío del conde de Luna. A pesar de la parquedad del tenor documental, se puede concluir que la elaboración de este tipo de padrones debía de tratarse de una realidad consolidada en la maquinaria hacendística del condado, aunque deberá esperarse al avance de la investigación para entender la auténtica relevancia de este tipo documental.

Palabras clave: Condes de Luna, Llamas de la Ribera, diplomática señorial, documentación fiscal.

Abstract: The 1480 tax census of Llamas de la Ribera (León) is the only example of its kind found in the archive of the Quiñones-Counts of Luna lineage. In spite of the utility that this kind of census has for a wide variety of historical works, we do not really know very much about them, especially from the Diplomatics standpoint. We thus focused on the study and edition of this manuscript, whose characterization may hopefully contribute to improving our knowledge of the medieval tax system and its documental expression in late medieval rural León. From a paleographical and diplomatic view we proceeded to edit its contents in order to undertake the consequent study of its internal and external 


\author{
Francisco JAVIER Álvarez CARBAJAL \\ EL PADRÓN FISCAL DE 1480 DE LLAMAS DE LA RIBERA (LEÓN)
}

features, in an attempt to understand the role played by this document in the administration of the municipalities under the rule of the Count of Luna. Despite the paucity of information found in the document, we can come to the conclusion that the elaboration of this type of census may have been a consolidated reality in the tax administration of the county, although we must wait to future research in order to fully understand the real importance of this document type.

Keywords: Counts of Luna, Llamas de la Ribera, seigneurial diplomatics, tax records.

\title{
INTRODUCCIÓN ${ }^{1}$
}

Los padrones constituyen una fuente importante para el estudio de la Baja Edad Media debido a la riqueza de su información, que permite la elaboración de monografías de toda índole. Así, multitud de historiadores han empleado este tipo de listados para acometer estudios históricos desde un sinnúmero de ópticas y temáticas diferentes: el papel de los concejos en la fiscalidad bajomedieval ${ }^{2}$, demografía $^{3}$, antroponimia ${ }^{4}$, diplomática fiscal ${ }^{5}$, aproximaciones socioeconómicas y socio-profesionales a minorías étnicas y religiosas ${ }^{6}$, etc.

\footnotetext{
${ }^{1}$ El presente trabajo se ha producido en el marco de una ayuda predoctoral de investigación del programa Severo Ochoa subvencionada por la Consejería de Educación del Gobierno del Principado de Asturias a través de la Fundación para el fomento en Asturias de la investigación científica aplicada y la tecnología (FICYT). Asimismo, queremos agradecer el apoyo de D. Manuel Carriedo Tejedo al frente del Centro de Documentación del Archivo Histórico de Caja España en el suministro de los materiales documentales necesarios para llevar acabo esta investigación.

2 J. M. MONSALVO ANTÓN, El sistema político concejil. El ejemplo del señorío medieval de Alba de Tormes y su concejo de villa y tierra, Salamanca, 1988. L. R. VILLEGAS DÍAZ, "El caso de la villa de Chillón (1525)", en Las ciudades andaluzas (siglos XIII-XVI). Actas del VI Coloquio Internacional de Historia Medieval de Andalucía, Málaga, 1991, pp. 189-199. F. J. ROMERO ROMERO, "El concejo como instrumento de la fiscalidad regia en la Castilla del siglo XV. Sevilla y los pedidos de Cortes (1406- 1474)", en Las ciudades andaluzas..., pp. 161-165.

${ }^{3}$ P. J. MONTEANO SORBET, "La población navarra a comienzos del siglo XVI. El Recuento de casas de 1514", Príncipe de Viana, año no 61, no 220 (2000), pp. 407-432. De hecho, el propio padrón de Llamas fue empleado para aproximarse a la población de uno de los núcleos bajo dominio del señorío de los Quiñones, vid. C. ÁLVAREZ ÁLVAREZ, El condado de Luna en la Baja Edad Media, León, 1982, p. 299, nota 14.

${ }^{4}$ P. MARTÍNEZ SOPENA, "Reflexiones sobre dos listas de hombres buenos: Lugo (1295) y Palencia (1300)", en Scripta. Estudios en homenaje a Élida García García, Oviedo, 1998, pp. 397-416.

${ }^{5}$ A. ROMERO MARTÍNEZ, Los papeles del fisco. Estudio diplomático de la documentación fiscal castellana bajomedieval, Granada, 1998; "El padrón, documento diplomático", Signo. Revista de historia de la cultura escrita, ${ }^{\circ} 6$ (1999), pp. 9-39.

${ }^{6}$ E. MARTÍN GUTIÉRREZ, "Nuevos datos sobre la población y los genoveses en la ciudad de Cádiz. Una relectura del padrón de vecinos de 1467”, En la España medieval, 29 (2006), pp.
} 


\section{Francisco JaVier Álvarez CARBAJAL \\ El PADRÓN FISCAL DE 1480 DE LLAMAS DE LA RiBERA (LEÓN)}

Pero es relativamente poco lo que aún sabemos de ellos, en particular para la época medieval. De hecho, Romero Martínez los califica de "realidad polivalente" con una casuística enorme en su proceso de elaboración y cuyos orígenes son muy difíciles de rastrear ${ }^{7}$. En este sentido, Herrero Jiménez ha subrayado recientemente que se trataba de una práctica poco normalizada y carente de un tipo documental claro, dado que su elaboración solía responder a necesidades puntuales y concretas ${ }^{8}$.

Partiendo de estas premisas, el propósito de este trabajo es el estudio y edición de un testimonio singular del Archivo de los Condes de Luna, cuya caracterización puede contribuir a conocer mejor el sistema contributivo y su plasmación documental en el mundo rural leonés de fines de la Edad Media, que aparece como algo muy alejado de lo que ocurría en los núcleos mayores del reino. El padrón de Llamas de Ribera de 1480 se conserva bajo la nomenclatura de $n^{\circ} 280$ del fondo de papeles de dicho Archivo ${ }^{9}$, tratándose de un documento excepcional dentro de su contexto archivístico, ya que es el único padrón encontrado hasta la fecha en el fondo documental del linaje. Más aún, la escasez de documentación de carácter fiscal a partir de la segunda mitad del siglo XV (tampoco hay libros de cuentas conservados, que sepamos) dificulta enormemente la reconstrucción del funcionamiento de la hacienda señorial. Sí se ha detectado, sin embargo, la existencia de diferentes oficiales (mayordomos, contadores, recaudadores, secretarios) que apuntan hacia la organización de una hacienda señorial claramente inspirada en el modelo regio ${ }^{10}$.

Desde el punto de vista de la investigación diplomática sobre padrones, Romero Martínez aportó el primer estudio que se abordó desde esta óptica diplomatista $^{11}$, no sólo de los padrones, sino de toda la documentación fiscal ${ }^{12}$. En su fundacional trabajo ofreció una primera clasificación tipológica de los padrones tomando como criterio la función de su acción jurídico fiscal. Breves, pero sin

187-223. C. CARRETE PARRONDO, “Talavera de la Reina y su comunidad judía. Notas críticas al padrón de 1477-1478”, En la España medieval. Estudios dedicados al profesor D. Julio González González, 1 (1980), pp. 43-57.

${ }^{7}$ A. ROMERO MARTÍNEZ, "El padrón...”, p. 10 y ss.

${ }^{8}$ M. HERRERO JIMÉNEZ, Padrones y registros notariales medievales abulenses en el Archivo de la Real Chancillería de Valladolid, Fuentes Históricas Abulenses. Ávila, 2010, p. 35.

${ }^{9}$ C. ÁlvareZ ÁlVAREZ, y J. A. MARTÍN FUERTES, Catálogo del Archivo de los Condes de Luna, León, 1977.

${ }^{10}$ C. ÁllVAREZ ÁlvareZ, El condado..., p. 363. Para estudios sobre la Hacienda Real, ver la obra de M. A. LADERO QUESADA, en especial para este trabajo La Hacienda real castellana entre 1482 y 1492, Valladolid, 1967.

${ }^{11}$ A. ROMERO MARTÍNEZ, "El padrón...".

${ }^{12}$ A. ROMERO MARTÍNEZ, Los papeles... 


\section{Francisco JaVier Álvarez CARBAJAL \\ EL PADRÓN FISCAL DE 1480 DE LLAMAS DE LA RIBERA (LEÓN)}

duda de gran utilidad por tratarse al igual que en nuestro caso de un señorío, resultan las indicaciones que aporta Pardo Rodríguez sobre los documentos referidos al reparto del servicio señorial en el condado de Medinaceli, cuya frecuencia y proliferación demuestran que su elaboración se hallaba consolidada ya en el último tercio del siglo $\mathrm{XIV}^{13}$. En fin, recientemente se ha publicado algún estudio diplomático más, como el de Herrero Jiménez, donde destaca su utilización como prueba de hidalguía en pleitos de época Moderna ${ }^{14}$.

\section{EL PADRÓN DE LLAMAS DE 1480}

En primer lugar, llama la atención su condición de documento notarial original, alejado por tanto de otros ejemplos estudiados hasta ahora (Medinaceli, Ávila ${ }^{15}$ ).

Generalmente, y como la investigación ha tratado ampliamente, el procedimiento de empadronamiento y recaudación recaía en los concejos ${ }^{16}$, que disponían de una gran libertad para reglamentar y administrar todo el proceso, lo que quizás explique la enorme casuística que sufre esta tipología documental, antes aludida. Por tanto, lo más normal era que fuese el escribano del concejo el encargado de escriturar toda la documentación referida al proceso de empadronamiento y tributación.

Sin embargo en el señorío de los Quiñones todas las funciones documentales parecen recaer en la misma instancia, el escribano público. De algunos años antes (1468) se conserva en el mismo archivo un interesante registro notarial ${ }^{17}$

${ }^{13}$ M. L. PARDO RODRÍGUEZ, Documentación del Condado de Medinaceli (1368-1454), Soria, 1993, p. 114.

${ }^{14}$ M. HERRERO JIMÉNEZ, Padrones...

${ }^{15}$ Los padrones de Olmedo (1482 y 1483, y de 1501 a 1504), fueron escritos por el escribano del cabildo de los pecheros de villa y tierra, que carecía de título de escribano, por lo que no fueron signados ni firmados. A pesar de no disponer de validación, el cabildo le daba credibilidad y fue un documento presentado en un pleito posterior. Vid. M. HERRERO JIMÉNEZ, Padrones..., p. 39. En cuanto a los repartimientos del condado de Medinaceli, a pesar de no ser padrones de personas, sino de lugares, comparten con los primeros un mismo propósito en el control administrativo de la población y recaudación de las rentas señoriales. Sin embargo, esta documentación en concreto no lleva suscripción del notario debido a que llegan en forma de copias simples. Vid. M. L. PARDO RODRÍGUEZ, Documentación..., p. 114.

${ }^{16}$ Vid. nota 2. En síntesis, podemos decir que, una vez recibido el mandato de, en este caso, la autoridad señorial, la labor del concejo consistía en la organización y reglamentación del proceso de recaudación (y en este sentido es donde se insertaba la elaboración de ordenanzas que sirviesen de marco regulador de padrones de cuantías) así como la elección de empadronadores y quitadores.

${ }^{17}$ Archivo Histórico de Caja España (A.H.C.E.), Condes de Luna, Papeles, 246. 


\section{FranCisco JAVIER Álvarez CARBAJAL \\ El PADRÓN FISCAL DE 1480 DE LLAMAS DE LA RiBERA (LEÓN)}

efectuado por otro escribano público, donde se observaba que unía en un mismo texto documentos privados y judiciales, así como testimonios para el concejo. Parece, pues, que los escribanos públicos nombrados por el titular de la casa desempeñaban una labor que no se circunscribía únicamente al ámbito del documento privado.

En este caso, se plantea una situación similar. Es responsable de su elaboración Pedro González de San Feliz, escrivano de nuestro sennor el rey e notario público en tierra del sennor conde de Luna. Doble condición ésta que parece repetirse en otros casos estudiados para escribanías públicas en jurisdicciones señoriales. Generalmente, un escribano debía acceder primero al cargo de notario público del rey como requisito indispensable para ser nombrado escribano por un señor $^{18}$.

Por desgracia, desconocemos el contexto archivístico de la pieza. No solamente no encontramos ningún otro ejemplar de esta tipología para ningún otro concejo del señorío, sino que no hemos encontrado más documentación de este escribano y el resto de ejemplares relacionados al concejo de Llamas de Ribera son marginales y de época muy posterior. No sabemos por qué se conservó ${ }^{19}$.

En lo referente a su caracterización externa, el padrón fue redactado en dos bifolios de papel cosidos a modo de pequeño cuadernillo que carece de cubiertas. $\mathrm{Su}$ escritura es la habitual en este tipo de documentos de carácter administrativo: gótica redonda cursiva ${ }^{20}$. Sólo detectamos una única mano en el documento, por lo que entendemos que toda la redacción fue efectuada por el dicho Pedro González. Se trata de una mano rápida, que produce notables cambios en el módulo de la escritura, unidos a una disposición del texto que tiende a inclinarse claramente, ofreciendo una impresión general de premura y falta de cuidado en su elaboración ${ }^{21}$.

El recuento no se dispone de manera ordenada. Por ejemplo, el listado de los vecinos de Azadón no se sitúa a continuación del registro perteneciente a Llamas, sino que se inicia en paralelo con la última columna del anterior, aprovechando

${ }^{18}$ M. L. PARDO RODRÍGUEZ, Señores y escribanos. El notariado andaluz entre los siglos $X I V y X V I$, Sevilla, 2002, p. 31.

${ }^{19}$ Dado que en la orden del conde se señala de manera implícita el interés por conocer a los hidalgos, podemos conjeturar sobre la posibilidad de que este padrón hubiese sido utilizado en algún pleito de época posterior como prueba de hidalguía, al igual que sucede con los padrones de Olmedo estudiados por Herrero Jiménez. Vid. M. HERRERO JIMÉNEZ, Padrones...

${ }^{20}$ Para una aproximación a la escritura gótica documental, vid. M. J. SANZ FUENTES, "La escritura gótica documental castellana", en Paleografía II, Las escrituras góticas desde 1250 hasta la imprenta, Oviedo, 2010, pp. 107-126.

${ }^{21}$ Ver anexos 1 y 2. 


\section{Francisco JAVIER Álvarez CARBAJAL \\ EL PADRÓN FISCAL DE 1480 DE LLAMAS DE LA RIBERA (LEÓN)}

todo el espacio del papel $^{22}$. Parece, por tanto, que el ahorro de espacio primó como criterio sobre la claridad en la elaboración del padrón. En cuanto a la disposición general de los nombres, éstos se agrupan formando columnas, que a veces parecen mantener una columna ideal, pero otras, en cambio, no. Todo ello nos conduce a especular sobre la falta de pericia o de costumbre en la elaboración de esta tipología documental por parte del escribano.

En cuanto a la validación del documento ${ }^{23}$, el escribano anotó su media rúbrica en las hojas escritas, que es doble en el folio $2 \mathrm{v}$ para cancelar las dos columnas de datos. Finalmente, el tenor se cierra con la suscripción notarial con su signo $^{24}$, incluyendo antes la referencia nominal de la presencia de tres testigos, de los cuales se especifica su vecindad en el propio concejo de Llamas de Ribera.

De su tenor documental parece desprenderse que este padrón, sobrevivido excepcionalmente, representa una parte del procedimiento habitual dentro del sistema de recaudación en el señorío de los Luna. No tiene sentido pensar que su realización se limitase únicamente a este concejo ya que, como señalamos al inicio, la presencia de oficiales de la hacienda señorial convierte en altamente improbable un uso tan rudimentario y marginal de la documentación fiscal ${ }^{25}$.

La acción la inicia el conde ${ }^{26}$, cuya carta fyrmada se dirige al concejo, entendemos que a todos los del señorío. El procurador Sirgado continúa la acción dirigiéndose al notario público, que actúa por autoridad judicial. Ahora bien, el tenor del padrón es tan parco en información que se nos plantean serias dudas sobre su proceso de elaboración. Es impensable que un padrón se pueda realizar de manera completa en un solo día. A pesar de no conservar la orden original del conde, lo más lógico sería plantear que ésta se produjese con días e incluso semanas de anticipación, nombrándose para cada término uno o dos jurados que actuasen como empadronadores, de tal forma que en realidad, aquel 7 de marzo de

\footnotetext{
${ }^{22}$ Obsérvese además cómo en el folio $2 \mathrm{v}$ se dificulta la individualización entre el listado de los hidalgos de San Román y el de los pecheros de Las Omañas.

${ }^{23}$ En los padrones de Olmedo no se detecta validación dado que el escribano de concejo carecía de la titulación profesional (ver nota 15). M. HERRERO JIMÉNEZ, Padrones..., p. 39.

${ }^{24}$ Ver Anexo 5.

${ }^{25}$ Lo mismo sucede con otras tipologías que fueron sometidas a un grado de destrucción masivo, como la de los registros notariales, cuya práctica en Castilla se demuestra extendida en la segunda mitad del siglo XV, aunque apenas conservemos unos cuantos ejemplares de época medieval. Este caso es paralelo en nuestra investigación, pues al igual que sucede con este padrón, sólo encontramos un ejemplar de registro notarial (A.H.C.E., Condes de Luna, Papeles, 246), cuyas características hacen altamente improbable que fuese el único producido dentro del señorío.

${ }^{26}$ En Medinaceli el reparto se hace siempre por mandado del señor jurisdiccional, vid. M. L. PARDO RODRÍGUEZ, Documentación..., p. 114.
} 


\section{Francisco JaVier Álvarez CARBajaL \\ El PADRÓN FISCAL DE 1480 DE LlAMAS DE LA RiBERA (LEÓN)}

1480, el escribano Pedro González estuviese, de alguna manera, unificando los padrones locales para conformar un único padron de todo el concejo.

De hecho, se podrá comprobar que el padrón de Llamas no refleja el patrimonio de los vecinos del concejo, sino que se limita a separar a la población pechera de la que que disfruta de exención fiscal (fundamentalmente clérigos, escuderos e hidalgos). El expositivo que se incluye al inicio del tenor es claro en cuanto a la causa de su realización y su segura utilización para un fin posterior ${ }^{27}$. Se trata, por tanto, de lo que Romero Martínez clasificaría como un padrón de tasación ${ }^{28}$, esto es, una vez calculado el patrimonio real de los vecinos se procede a la estimación de las cáñamas ${ }^{29}$ o tramos fiscales con los que deberán contribuir a la hacienda señorial.

El recuento se distribuyó por localidades, siguiéndose este orden: Llamas de Ribera, Azadón, Secarejo, Villarroquel, San Román de los Caballeros, Las Omañas, Paladín y Andarraso. En ningún momento encontramos indicios de que el escribano se haya desplazado personalmente a estos términos, más bien el padrón fue redactado en Llamas, a donde se trasladaron vecinos desde los diferentes términos del concejo. Antes de anotar el padrón de cada pueblo, se incluye el juramento de dichos vecinos ${ }^{30}$ y a continuación se diponen las listas, empezando por los pecheros y anotando después a los fiscalmente privilegiados. El recuento de pecheros se organiza en base a tres columnas ideales, más o menos respetadas por el escribano. En la primera se anota el nombre, que suele incluir nombre de pila y apellido, pudiendo incluirse vecindad, estado civil, oficio,

${ }^{27}$ (...) por manera que fuesen declarados los fidalgos e los clérigos de con los labaradores; $e$ asý declarados que pedía a mí, sobredicho notario, los asyntase e je los diese escriptos e sygnados de mi sygno. Es decir, el padrón se efectúa no para conocer el patrimonio de los vecinos, sino para diferenciar a la población pechera de la que no lo es. También se presume que posteriormente el conde utilizará dicha información para otro fin, como se deduce de para lo apresentar al sennor conde e para que su merçed mande lo que se a de fazer.

${ }_{28}$ A. ROMERO MARTÍNEZ, "El padrón...", p. 17.

${ }^{29}$ La mejor aproximación a la problemática que supone el carácter polisémico del concepto de "cáñama" la ofrece, a nuestro modo de ver, J. M. MONSALVO ANTÓN, El sistema político..., p. 379 y ss. También Carretero Zamora ha reflexionado sobre este término. Vid. J. M. CARRETERO ZAMORA, La averiguación de la Corona de Castilla, 1525-1540. Los pecheros y el dinero del reino en la época de Carlos V, Salamanca, 2008, pp. 383-384.

${ }^{30}$ A falta de más información, pueden tratarse de los jurados a los que se refiere Romero Romero, cuyo papel es el de contactar con el pechero, siendo el último eslabón de la cadena fiscal. Este autor afirma que estos jurados debían responder con sus bienes ante las autoridades superiores. Sus funciones consistían en colaborar con los recaudadores y oficiales del concejo, participar en la confección de padrones y cuantías en sus barrios y collaciones, y actuar como representantes de los vecinos, siendo sus representantes en el concejo y dando fe de su vecindad. Podían incluso ser los encargados de llevar a cabo la recaudación en sus barrios, por lo que a veces disponían de medios coercitivos, como el embargo. Vid. F. J. ROMERO ROMERO, “El concejo...”, p. 164. 
apodo, filiación, etc. A continuación se dipone otra columna con la parte proporcional del pago de la renta a la que tienen que hacer frente, esto es, la cáñama. Finalmente, la tercera columna la conforman las cantidades de ese tramo fiscal al que cada vecino debe hacer frente, que curiosamente siempre es una cáñama, y que se anota mediante el numeral romano I y lo que creemos que podría ser la abreviatura de la palabra cáñama. Una vez finalizado el recuento, y antes de pasar a la columna de privilegiados, se anota la suma de todas las cáñamas, de nuevo en numerales romanos y con la abreviatura de la palabra cáñamas ${ }^{31}$.

A continuación se dispone el recuento de los privilegiados de la localidad en cuestión. En este caso, su disposición adopta únicamente dos columnas. En la primera se anota el nombre del vecino, casi siempre con el apellido o, en su defecto, la vecindad. En la segunda columna se anota su condición de privilegio. La mayoría son hidalgos, en cuyo caso se registra fidalgo para los varones (salvo en raras excepciones en las que se optó por la voz fijodalgo) y fijadalgo para las mujeres. También se localizan clérigos y escuderos exentos de tributar.

Mezclados con los pecheros e hidalgos habría un tercer grupo de vecinos a los que se empadrona con la expresión en descuento ${ }^{32}$ y que probablemente se correspondan con la población exenta de tributar por carecer de un patrimonio mínimo que no les permitiría siquiera alcanzar la cáñama menor.

\footnotetext{
${ }^{31}$ Por eso creemos que podría tratarse de la abreviatura de cáñama. La abreviatura empleada es sumamente simple, lo cual dificulta enormemente su interpretación. Está conformada únicamente por lo que parece ser una $c$ con el signo de abreviación en su parte superior. Sin embargo, cabe recordar que para este tipo de escrituras góticas redondas cursivas, las letras $c$ y $t$ tienden a confundirse, dificultando su individualización, más aún cuando en este caso carecemos de un contexto más amplio, es decir, de otras letras que nos permitan desarrollar con mayor precisión y seguridad la palabra completa. Ahora bien, cuando se realiza el recuento y la suma de las cáñamas, la palabra que acompaña al numeral debe estar, por fuerza, en plural. En este caso, a la $c$ con signo de abreviatura se añade una $s$ que indica ese plural, lo cual nos induce a pensar que, efectivamente, podría tratarse de la palabra cáñama y cáñamas, respectivamente. Ver anexo 3.

${ }^{32}$ En realidad se anota con una abreviatura de difícil interpretación y que nosotros hemos desarrollado en "descuento" por tratarse de un término cuya existencia hemos podido comprobar para tal época. Sea lo que fuere, se corresponde con vecinos con exención fiscal, pero no por derecho de hidalguía, sino porque probablemente su patrimonio no llegase a la cáñama menor (obsérvese el número de viudas anotadas bajo esta categoría, lo cual parece apoyar nuestra interpretación). Lo cierto es que no son contabilizados entre la población que debe contribuir a las cáñamas, por lo que creemos que la expresión "en descuento" se identificaría con esta particularidad que registra el padrón. Ver anexo 4.
} 


\section{CONCLUSIÓN}

Como señalábamos al inicio de nuestro artículo, el estudio de este tipo de padrones supone una enorme fuente de conocimiento en la elaboración de discursos históricos dada la enorme variedad de temáticas de investigación a la que pueden servir. Esperamos con este modesto estudio contribuir a tal fin, siendo conscientes de las limitaciones que han impuesto la parquedad del tenor documental y la imposibilidad de desentrañar su contexto archivístico. El padrón de Llamas de 1480 supone un documento de indudable singularidad, al que acaso en un futuro, y siempre a la luz de nuevos hallazgos, se pueda volver y reinterpretar en un contexto, esperemos, mejor conocido. Quizás de esta forma este listado de nombres contribuya a comprender mejor el funcionamiento interno de los concejos del condado de Luna o la organización de la hacienda señorial del conde, sin mencionar el singular papel que parecen jugar las escribanías públicas en el engranaje de los mecanismos de poder y legitimación del señorío de los Quiñones. 
1480, marzo, 7. Llamas de la Ribera.

Pedro González de San Feliz, notario público en el señorio del conde de Luna, levanta acta del padrón de vecinos de Llamas de la Ribera, a petición de su procurador Fernán Sirgado presentada ante el juez del concejo, Rodrigo de Cuéllar.

A.-Papel, un pliego de 4 hojas, la última en blanco, de 22 x 15,5 cm. Media rúbrica del notario en las hojas escritas, que es doble en $2 \mathrm{v}$ para cancelar las dos columnas de datos.

León, Archivo Histórico de Caja España, fondo de los Condes de Luna, papeles, nº 280.

Reg.: C. ÁlVAREZ ÁLVAREZ, César y J. A. MARTín FUERTES, Catálogo del Archivo de los Condes de Luna. León, 1977, pp. 97.

Cit.: C. ÁLVAREZ ÁLVAREZ, César, El condado de Luna en la Baja Edad Media, León, 1982, pp. 299, nota 14; pp. 321, nota 78 .

En Llamas, martes siete días del mes de março, anno del nascemiento del nuestro sennor Ihesu Christo de mill e quatroçientos e ochenta annos, e en presençia de mí, Pero Gonçález de Sant Feliz, escrivano de nuestro sennor el rey e notario público en tierra del sennor conde de Luna, e de los testigos de juso escriptos, estando este dicho día Rodrigo de Cuéllar, juez hordynario en el dicho conçejo por el dicho sennor conde, aparesçió ende de presente Fernán Syrgado, procurador en el dicho conçejo. E luego presentó una carta fyrmada del senor conde, e dixo que pedía al dicho juez él quesyese tomar juramiento de çiertos onbres que ende estavan presentes de los lugares del dicho conçejo para que, por virtud de los dichos juramientos, por ante mí sobredicho notario feziesen el padrón de los veçinos de los dichos lugares segund en la dicha carta se contenía, por manera que fuesen declarados los fidalgos e los clérigos de con los labaradores; e asý declarados que pedía a mí, sobredicho notario, los asyntase e je los diese escriptos e sygnados de mi sygno para lo apresentar al sennor conde e para que su merçed mande lo que se a de fazer.

Los quel dicho juez luego tomó e resçebió juramiento sobre la dicha razón son estos que se syguen.

Primeramente, del dicho lugar de Llamas, juraron el dicho Fernán Syrgado e Martýn Fernández; los que dexieron por los dichos juramentos son estos que se syguen:

$\begin{array}{lll}\begin{array}{l}\text { Ferrán Martínez } \\ \text { Juan Domínguez } \\ / /{ }^{1 \mathrm{v}}\end{array} & \begin{array}{l}\text { en cáñama } \\ \text { cáñama }\end{array} & \begin{array}{l}\text { I cáñama } \\ \text { I cáñama }\end{array} \\ \begin{array}{l}\text {-Lope de Toro } \\ \text {-Diego Fernández } \\ \text {-Sancha Fernández, } \\ \text { biuda }\end{array} & \begin{array}{l}\text { cáñama } \\ \text { cáñama } \\ \text { en descuento }\end{array} & \begin{array}{l}\text { I cáñama } \\ \text { I cáñama }\end{array} \\ \begin{array}{l}\text {-Juan Mestre } \\ \text {-Alonso Fernández el } \\ \text { moço }\end{array} & \begin{array}{l}\text { cáñama } \\ \text { cáñama }\end{array} & \begin{array}{l}\text { I cáñama } \\ \text { I cáñama }\end{array} \\ \text {-Pero Fernández } & \text { cáñama } & \text { I cáñama }\end{array}$




\begin{tabular}{|c|c|c|c|c|}
\hline -Leonor Alonso, biuda & en descuento & \multirow{2}{*}{\multicolumn{3}{|c|}{ I cáñama }} \\
\hline -Pero Alonso & cáñama & & & \\
\hline -Diego Luego & cáñama & \multicolumn{3}{|l|}{ I cáñama } \\
\hline -Alonso Franco & cáñama & \multicolumn{3}{|l|}{ I cáñama } \\
\hline -El Ferero & cáñama & \multicolumn{3}{|l|}{ I cáñama } \\
\hline -Juan Aparicio & cáñama & \multicolumn{3}{|l|}{ I cáñama } \\
\hline -Juan Conde & cáñama & \multicolumn{3}{|l|}{ I cáñama } \\
\hline -Antón & cáñama & \multicolumn{3}{|l|}{ I cáñama } \\
\hline -Ferrán Syrgado & cáñama & \multicolumn{3}{|l|}{ I cáñama } \\
\hline -Pero Prieto & cáñama & \multicolumn{3}{|l|}{ I cáñama } \\
\hline -Pero Gonçález & cáñama & \multicolumn{3}{|l|}{ I cáñama } \\
\hline -Juan Prieto el viejo & cáñama & \multicolumn{3}{|l|}{ I cáñama } \\
\hline -Su fijo Pedro & cáñama & \multicolumn{3}{|l|}{ I cáñama } \\
\hline -Juan Françisco & cáñama & \multicolumn{3}{|l|}{ I cáñama } \\
\hline \multicolumn{5}{|l|}{$\begin{array}{l}\text {-Alonso Martínez } \\
\text { tynajo }\end{array}$} \\
\hline -El Ryesco & en descuento & & & \\
\hline -Martýn Fernández & cáñama & \multicolumn{3}{|l|}{ I cáñama } \\
\hline -Juan Prieto el moco & cáñama & \multicolumn{3}{|l|}{ I cáñama } \\
\hline -Ferrán Pérez & cáñama & \multicolumn{3}{|l|}{ I cáñama } \\
\hline -Diego Alonso & cáñama & \multicolumn{3}{|l|}{ I cáñama } \\
\hline -Gómez Fernández & cáñama & \multicolumn{3}{|l|}{ I cáñama } \\
\hline -Gonçalo Hordónez & fidalgo & -María Garçía & \multicolumn{2}{|l|}{ fijadalgo } \\
\hline -Diego Hordónez & fidalgo & $\begin{array}{l}\text {-Marta Ramílez } \\
\text {-Juan de Llamas }\end{array}$ & $\begin{array}{l}\text { fijadalgo } \\
\text { fijodalgo }\end{array}$ & \\
\hline \multicolumn{5}{|c|}{ 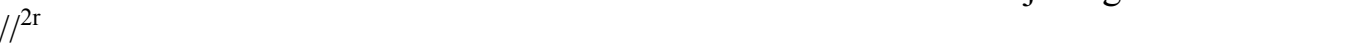 } \\
\hline -Gonçalo Fernández & fidalgo & & & \\
\hline -María Gonçález & fijadalgo & \multicolumn{3}{|c|}{ En Çadón juró Mary Garçía } \\
\hline -Lope Álvarez & fidalgo & \multicolumn{3}{|l|}{ byuda } \\
\hline -Pero Martínez & clérigo & $\begin{array}{l}\text {-Juan Martínez } \\
\text {-Miguel }\end{array}$ & $\begin{array}{l}\text { cáñama } \\
\text { cáñama }\end{array}$ & $\begin{array}{l}\text { I cáñama } \\
\text { I cáñama }\end{array}$ \\
\hline -María Rodríguez & fijadalgo & -Juan Fernández & cáñama & I cáñama \\
\hline -María Álvarez & fidalga & -Martýn Fernández & cáñama & I cáñama \\
\hline -Martýn Álvarez & fidalgo & -Andrés Fernández & cáñama & I cáñama \\
\hline -Leonor Fernández & fijadalgo & -Alonso Martínez & cáñama & I cáñama \\
\hline -Fernán Hordónez & fidalgo & -Ferrán Sardón & cáñama & I cáñama \\
\hline & & -Juan Díaz & cáñama & I cáñama \\
\hline & & -Martýn Garçía & cáñama & I cáñama \\
\hline & & -Juan de Cadón & cáñama & I cáñama \\
\hline & & -María Cordera & en descue & \\
\hline & & -Marta Gonçález & en descue & \\
\hline & & -Beneyto Garçía & fidalgo & \\
\hline En Secarejo juró André & Garçía & & $\mathrm{X}$ cáñam & \\
\hline -Larallo & cáñama & I cáñama & gos: Alc & so Álvarez. \\
\hline
\end{tabular}

${ }^{33}$ Tachado: Fernán Sardón. 


\begin{tabular}{|c|c|c|c|c|}
\hline -Alvar Gonçález & cáñama & I cáñama & \multirow{2}{*}{\multicolumn{2}{|c|}{$\begin{array}{l}\text {-Gonçalo del Prado } \\
\text {-Pedro Fernández }\end{array}$}} \\
\hline -María Alonso biuda & cáñama & I cáñama & & \\
\hline -Gonçalo Ferero & cáñama & I cáñama & & \\
\hline -Andrés del Campo & cáñama & I cáñama & & \\
\hline -Lope del Campo & cáñama & I cáñama & & \\
\hline -Martýn del Campo & cáñama & I cáñama & -En Villarroquel & \\
\hline -Miguel Garçía & cáñama & I cáñama & -Juan Álvarez & I cáñama \\
\hline -Alvar Alonso & cáñama & I cáñama & -Ynés Gonçález & I cáñama \\
\hline -Juan de la Casta & cáñama & I cáñama & -Gonçalo Ximejo & I cáñama \\
\hline -Luys Alonso & cáñama & I cáñama & $\begin{array}{l}\text {-María de la } \\
\text { Garga }\end{array}$ & I cáñama \\
\hline -Andrés Garçía & cáñama & $\begin{array}{l}\text { I cáñama } \\
\text { XII cáñamas }\end{array}$ & $\begin{array}{l}\text {-María Alonso } \\
\text {-Ynés Alonso byu } \\
\text { descuento }\end{array}$ & $\begin{array}{l}\text { fijadalgo } \\
\text { la en }\end{array}$ \\
\hline
\end{tabular}

$$
/ /^{2 \mathrm{v}}
$$

En Sant Román juró Gonçalo Fernández.

-Luys Alonso
-Juan Ferero
-Alvar Cordero
-Gonçalo Fernández
-Juan Blanco
-Teresa Garçía byuda
-Alvar Fernández
-Fernán Hordónez
-Gonçalo Díaz
-Teresa Fernández
-Juan Gotyérrez
-Fernán Gotyérrez
-Lope Díaz
-Zalo Díaz
-Lope Fernández
-La Ryesca
-María de Santa María
-María Alonso vieja

$\begin{array}{ll}\text { en cáñama } & \text { I cáñama } \\ \text { en cáñama } & \text { I cáñama } \\ \text { cáñama } & \text { I cáñama } \\ \text { cáñama } & \text { I cáñama } \\ \text { cáñama } & \text { I cáñama } \\ \text { en descuento } & \end{array}$

en descuento $\mathrm{V}$ cáñamas

-En las Homañas juró Pedro Martínez

$\begin{array}{ll}\text { escudero } & \text {-Juan González } \\ \text { fidalgo } & \text {-Pedro el calvo } \\ \text { escudero } & \text {-Pero Blanco }\end{array}$

el crespo

$\begin{array}{llll}\text { escudero } & \text {-Pero Blanco } & \text { cáñama } & \text { I cáñama } \\ \text { fijadalgo } & \text {-Juan Martínez } & \text { cáñama } & \text { I cáñama } \\ \text { fidalgo } & \text {-Pero Martínez } & \text { cáñama } & \text { I cáñama } \\ \text { fidalgo } & \text {-Juan de Magaz } & \text { cáñama } & \text { I cáñama } \\ \text { escudero } & \text {-Alonso Rodriguez } & \text { cáñama } & \text { I cáñama } \\ \text { clérigo } & \text {-Pero Alonso } & \text { cáñama } & \text { I cáñama } \\ \text { clérigo } & \text {-Juan Pérez el viejo } & \text { cáñama } & \text { I cáñama } \\ \text { fijadalgo } & \text {-Martyna Alonso } & \text { cáñama } & \text { I cáñama } \\ \text { fijadalgo } & \text {-Beneyta Pérez } & \text { cáñama } & \text { I cáñama } \\ \text { en descuento } & \text {-Juan Pérez el moço } & \text { cáñama } & \text { I cáñama } \\ & \text {-Alonso Pérez } & \text { cáñama } & \text { I cáñama } \\ & & \text { XIII } & \end{array}$

-María Pasina no en descuento

tyene nada

-Juan Ares fijodalgo

-Lope Gonçález fidalgo

-Lope Gómez fidalgo

-Ynés Álvarez fijadalgo

$/ / 3 \mathrm{r}$

-Alonso Martínez de Canales juró por Paladýn e por Andaraso primeramente

-Pero Lovo de Paladýn

-Gonçalo Fernández

-Alonso de Canales

$\begin{array}{ll}\text { cáñama } & \text { I } \\ \text { cáñama } & \text { I } \\ \text { cáñama } & \text { I }\end{array}$


Francisco JAVIER Álvarez CARBAJAL

EL PADRÓN FISCAL DE 1480 DE LLAMAS DE LA RiBERA (LEÓN)

-Alonso Peláez

-Beneyto

-La de Juan Tecedor

-La que quedó de Calello

-Alvar Fernández

-Pedro Osorio en

-Aparicio en

$\begin{array}{ll}\text { cáñama } & \text { I } \\ \text { cáñama } & \text { I } \\ \text { cáñama } & \text { I } \\ \text { en descuento } & \end{array}$

VI

fidalgo avida razón

cáñama I

cáñama I

-Ares Gonçález

fijodalgo

-Alonso Melior fijodalgo

-La madre de Ares Gonçález fijadalgo

A la quel declaración de juramientos segund pasó por los sobredichos ajuramentados el dicho Fernán Syrgado, procurador del dicho conçejo, dixo quél pedía a mí el dicho notario que je lo diese asý escripto e sygnado de mi sygno para su guarda e del senor conde. Lamas.

Testigos, Diego de Laguna e Alvar Fernández e Lope Álvarez, veçinos de

E yo Pero Gonçález que por virtud de los dichos e declaraciones de testigos este padrón escreví e por ende puse aquí este mi syngno que es tal, en testimonio de $(\mathbf{S})^{34}$ verdá.

\footnotetext{
${ }^{34}$ En el signo, Pero Gonçález, notario.
} 
Francisco JAVIER ÁlVAREZ CARBAJAL

EL PADRÓN FISCAL DE 1480 DE LLAMAS DE LA RIBERA (LEÓN)

ANEXO 1

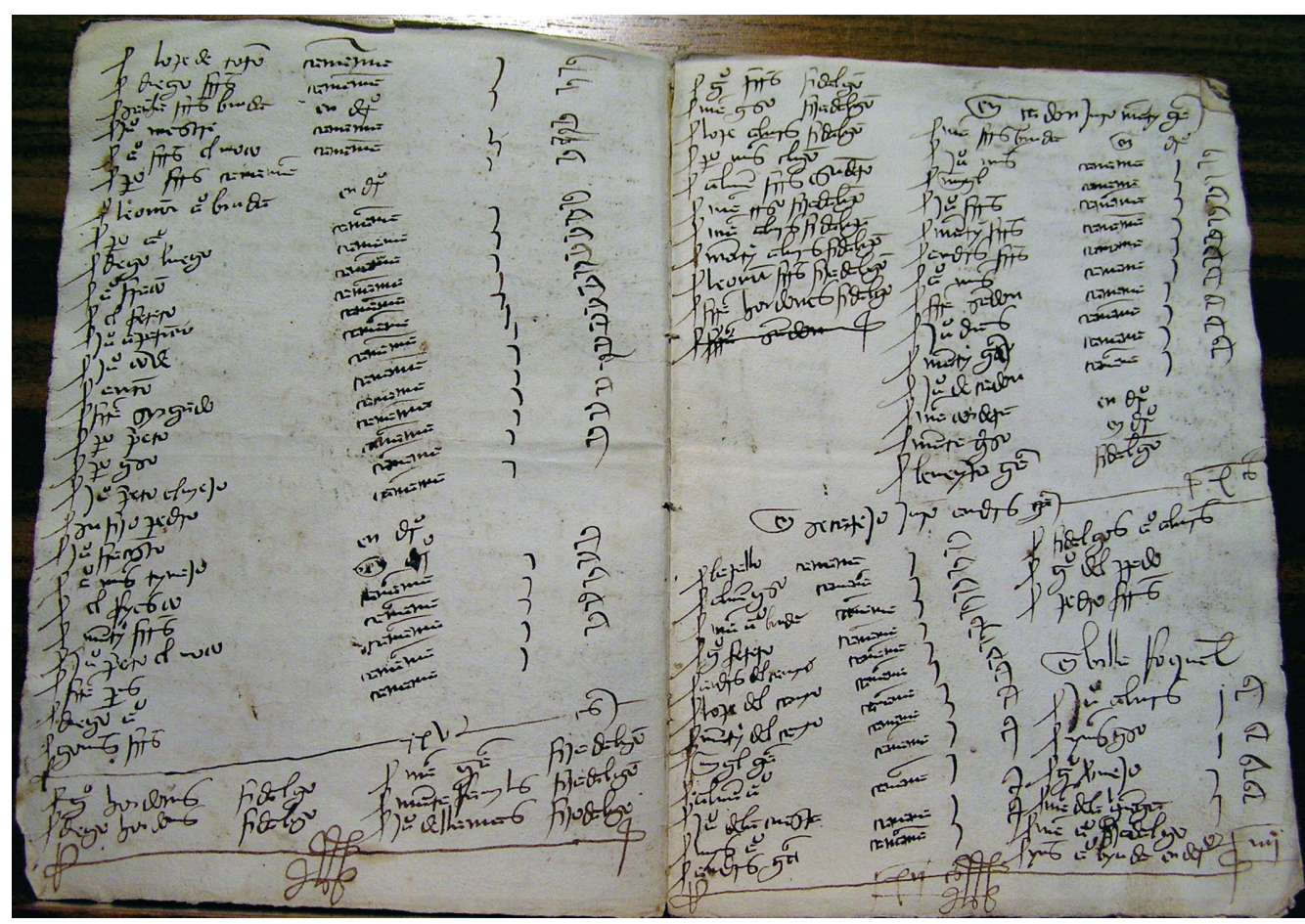

ANEXO 2

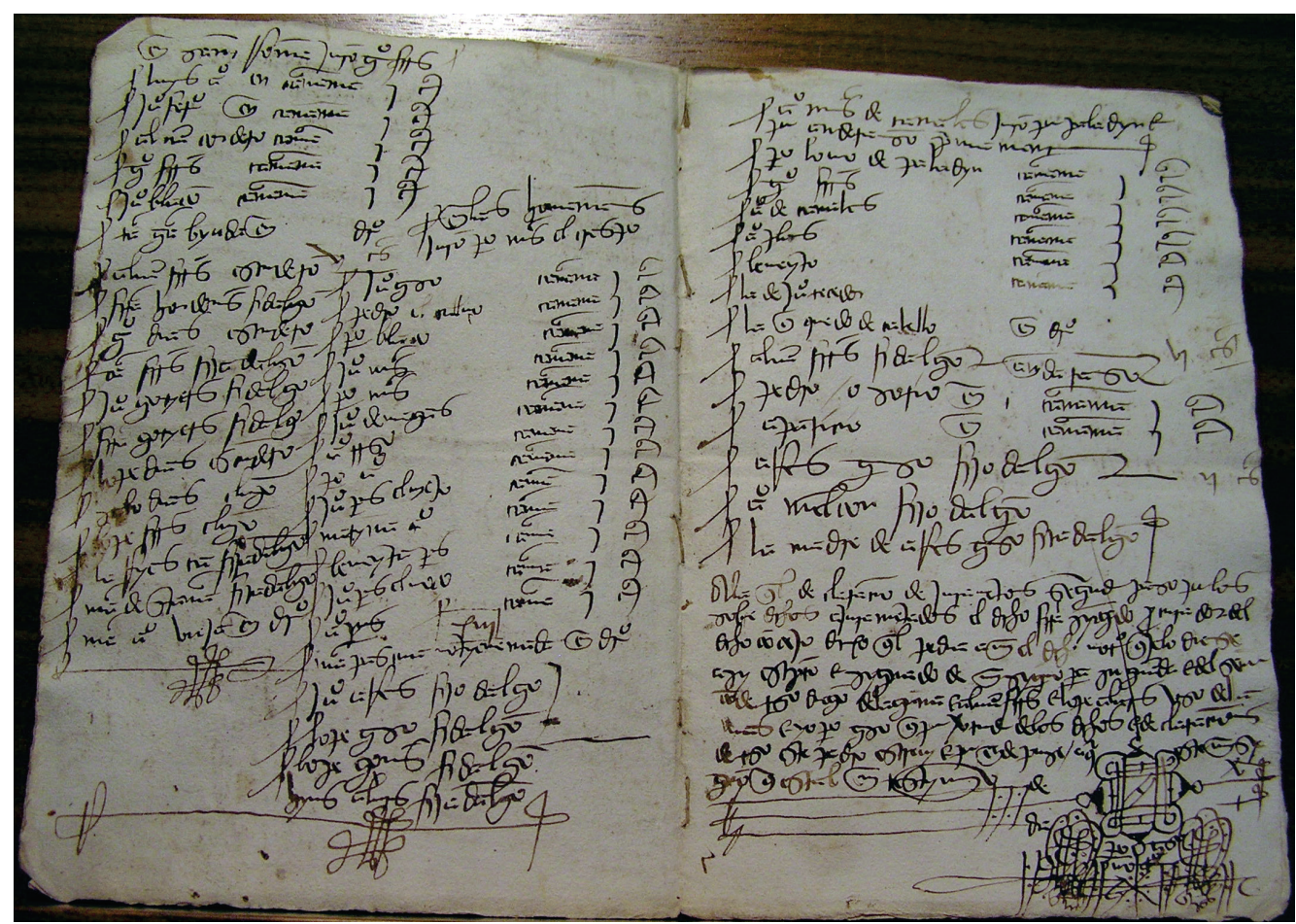


FranCISCO JAVIER ÁlvarEZ CARBAJAL

EL PADRÓN FISCAL DE 1480 DE LLAMAS DE LA RIBERA (LEÓN)

ANEXO 3

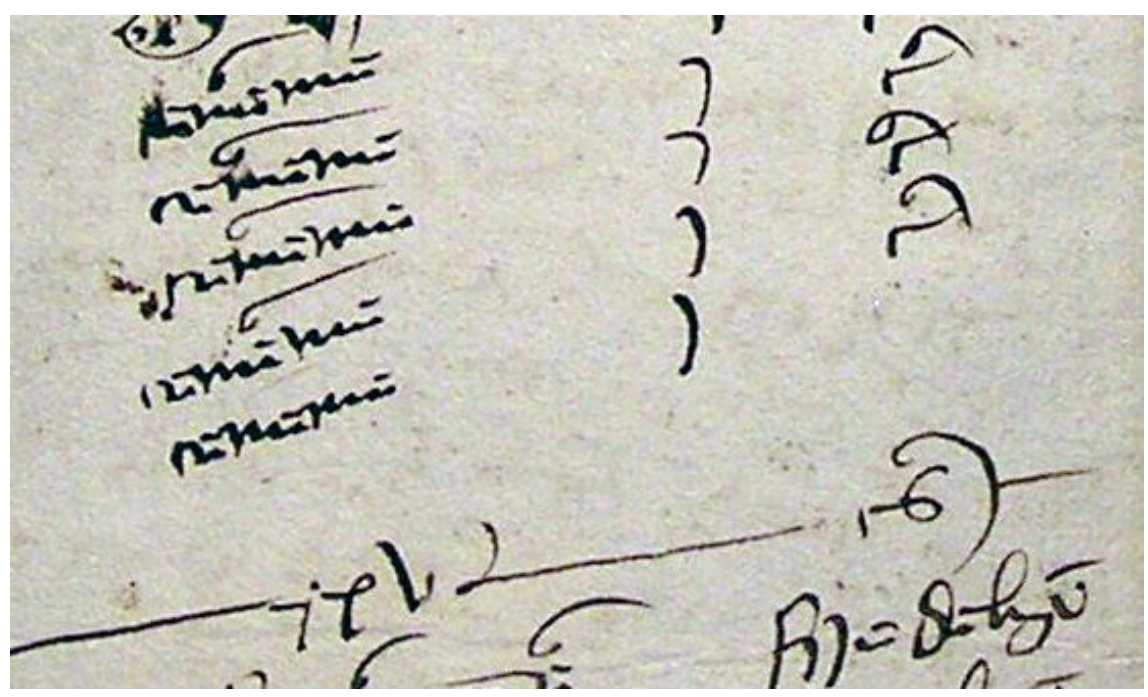

ANEXO 4

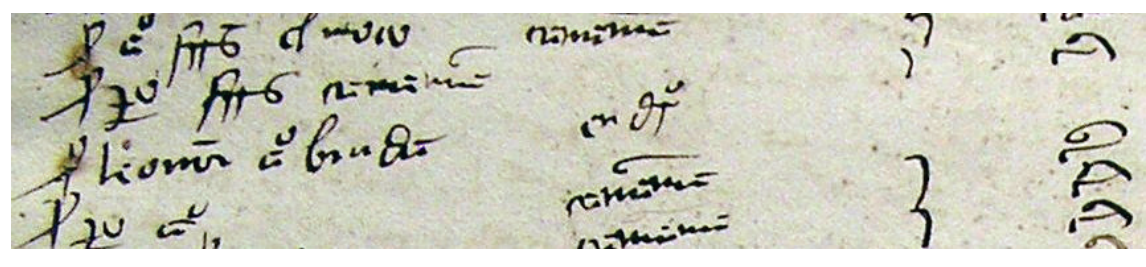

ANEXO 5

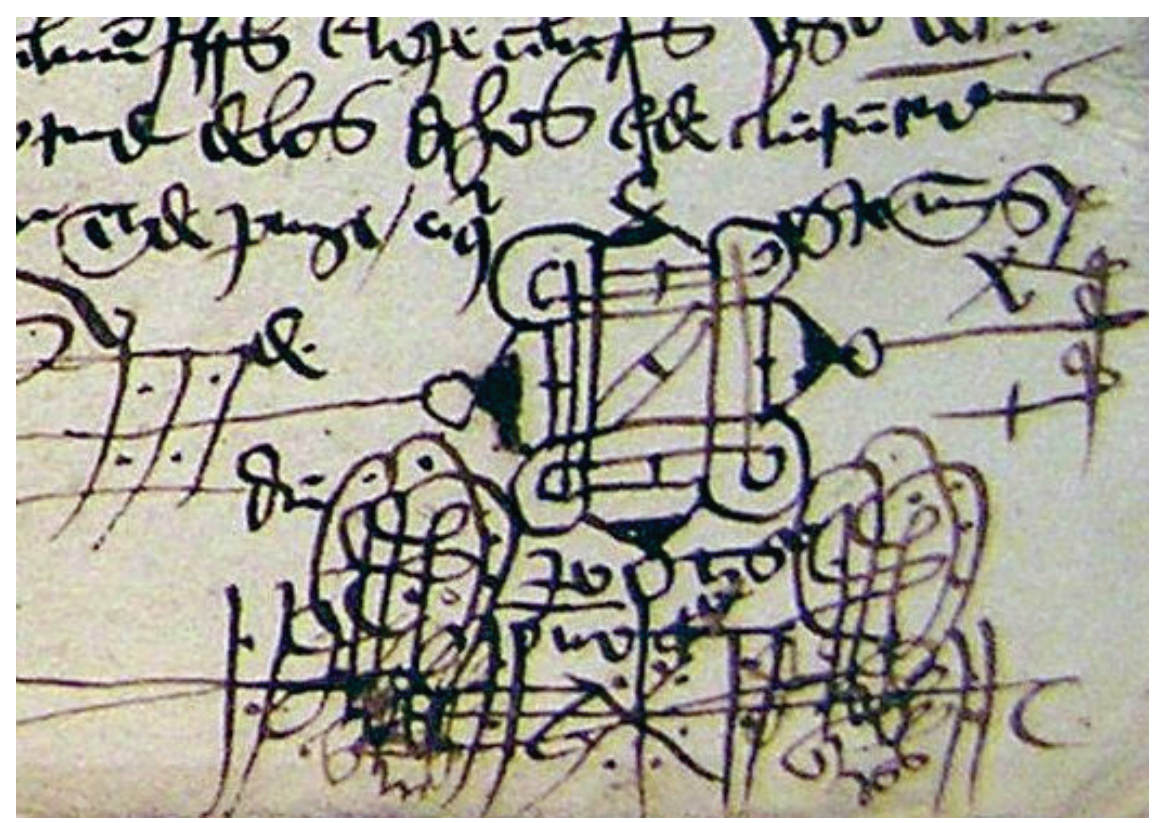

